\title{
Disabled People Data Management using GIS-DSS : Songkhla Province, Thailand
}

\author{
Sasalak Tongkaw ${ }^{1, *}$ and Aumnat Tongkaw ${ }^{2}$ \\ ${ }^{1}$ Faculty of Science and Technology, Songkhla Rajabhat University, 160 Kanjanawanit Road, Moung \\ Songkhla, Songkhla, 90000, Thailand \\ ${ }^{2}$ Faculty of Science and Technology, Songkhla Rajabhat University, 160 Kanjanawanit Road, Moung \\ Songkhla, Songkhla, 90000, Thailand
}

\begin{abstract}
This paper outlines the design and development of a prototype: GIS Decision Support System (GIS-DSS) on web-based and mobile application, for resource management, resource assessment, and to increase environmental quality by using disabled people data in Songkhla province, Thailand. This paper integrated GIS and DSS together and implemented on two platforms. First, for web frontend, using AngularJS and jquery technology over a Google API, and second, for mobile application, using node.js, the GIS technology used to support data access and process in both web-based and mobile application platform. The prototype DSS framework was applied to simulate the disabled facilities around the Songkhla province and other public areas. This paper intends to develop the prototype GIS-DSS into a full-fledged tool harnessed to enable better management and plan the future Songkhla smart city.
\end{abstract}

\section{Introduction}

There are many uses of geographic information systems in the management field, especially for Decision Support Systems for disabled people information. The convenience for the disabled people is essential for the modernization of the smart city. This research is to provide real information for the disabled in Songkhla. All disability data is analyzed for consistency and linkage in the design of decision support systems (DSS) so that senior management can use it to determine investment decisions to build facilities or investment in various projects.

There are many varieties of research on information systems for people with disabilities. Most often it directly aims to help the disabled. For example, the development of programs for visually impaired persons and mobile web-based tools for visually impaired children. The use of English instructional media and the satisfaction of visually impaired youth are considerations to the benefit of English language teaching programs for visually impaired youth. [1] Another research is also consistent with this research, which is on developing a mobile web-based auto-focus tool for visually impaired people, who aim to help visually

* Corresponding author: sasalak.to@skru.ac.th 
impaired people access the content quickly and to enable people with reading disabilities to read the text through the program. The application also features audiobooks for the visually impaired on mobile devices. The purpose of this study was to study the blind in Khon Kaen school in education through the use of print media and mainly printed materials, which render a blind person to aid their ability to interpret contents. [2] Computer teaching for journalism for visually impaired students whose purpose is to study the development of computer-aided instruction for journalism for visually impaired students in standard classes. [3] Optimizing Web Accessibility for Visually impaired people has the objective of reducing the symptom of their blindness and information technology limitations, reducing the social gap in the digital age and increasing the accessibility of information on the web for the visually impaired.[4] The use of smartphones with detection techniques is intended to assist the disabled and the vulnerable such as moving arms, hands and fingers. [5] A research example is control of smartphone operation with eye movement detection technique on the Android operating system for arm disabilities. The purpose is for the system to use the application of the eye to command the operation. Processed with digital imaging algorithms to integrate analytical frogs to calculate the position of the eye. Eye movement detection in the cursor controls the arm to be able to grasp correctly. The research has introduced the program such as application framework, libraries, Android Runtime, hardware abstraction layer, Linux kernel. Therefore, the operation of the program can detect the face and find the position of the eye accurately. [6] The research mentioned above is all research related to the blind. It is a research that helps visually impaired students, for instance, to increase the efficiency of the instructor and to ease the burden of the teaching instructor. The instructor can innovate a learning method for students with the visually impaired to bring laptop computers to assist them. Students would be able to distinguish the specific features of each computer program. Web page and display layout are optimized for visually impaired users. It reduces the barriers reaching user interfaces that rely on devices such as the mouse, which only allows the users to access some parts. The webpage contains vital printing which enables users to operate and control components such as menus or content that cannot be obtained by the visually impaired to create equality in digital society.

The loans on the disabled Geographic Information System (GIS) is used to produce and present information in a form that enables the development of systems to support decisionmaking. The data is processed as support. The allocation of funds for the loan in each province can meet the needs of the service. The useful reports to managers are to help to address the increased risk of the needs of stakeholders in geographic information systems that may be the basis for such systems. [7]

Geographic information systems can be widely used and associated with decisionmaking systems for executives. A prominent example of such an analysis is exploring the accessibility to public transport in the urban areas of the disabled: the use of geographic information systems is aimed at improving public transportation which could be accessed by all users, including people with disabilities and the elderly. The goal of this work is to create a new database that integrates especially with disabilities, places, and accessibility. [8]

The technology used for the elderly is prevalent, such as the system for attending and warning people of falling over for the elderly. The purpose of this research is to develop a system to seek help and alert a situation of falling over of elderly persons. [9] Another analysis is compatible with this research is a tool for the detection of a condition of old falling over with a sensor. Designing falls exposure for the elderly by using the application of the tilt sensor, which aims to prevent the fall of the elderly and to provide safety to the elderly when it is windy. [10] This is consistent with the research mentioned above, an expanding@home technology for older people and people with disabilities. The purpose is 
to help older people and people with disabilities to stay independent for as long as possible. [11] The system has introduced the Mercury Switch, PIC16F627A, Zigbee, tilt sensor GP1S036HEZ, Opto- Isolator, quality healthcare applications, application-created research, tools, and interfaces to collect and process data by medical devices and sensors to accommodate the elderly.

Market regulations are intended to tighten social relationships and attitudes towards disabled people, which focuses position on the poor and vulnerable. The disadvantage is associated with the calculation of costs and the inclusion in the social psychology of trafficking as a particular person, which makes the people especially enthusiastic about the action. Calculation Relationship between attitudes towards the disabled is perceived costs and benefits as mediators. [12]

Promoting high-speed internet access and ICT for the disabled: A comparative analysis of initiatives in the Asia-Pacific region that aims to improve the lives of people with disabilities, those that has inequality in access and usage among all the population. [13] The above research focuses on the requirements of the elderly and the disabled. Computer research is focusing on creating a context that is universally recognizable for caring and monitoring a person under attention. We have a vision of how to expand these systems in the future. In the future, there will be extensive interaction with the infrastructure in urban environments, in particular, the use of mobile phones, GIS, GPS, public cameras and other technologies. Presently, the data is generated and transmitted through the city, and this can then be used as input to intelligent and contextual infrastructure using software and hardware agents assisting the people.

Living in the old town with a high population amount of the elderly, for instance as living in the old city of Australia, [14] the research is consistent with the OCarePlatform Research: Care for Older Chronic Disease Institute in Elderly Caregivers. This has a purpose of reducing the burden of health services. Those living independently at home can be facilitated by offering them and the caregiver formal care and attention to their daily needs. [15]

By using appropriate information networks and infrastructure, it is crucial to improving social and economic research as well as the benefits of evaluating judgment and public policy planning that is accepted at this time. [8] The system introduced the ArcView 3.2 program, and it's public transport system to reach out to the underprivileged.

The design of the GIS application management for disabled people is the previous framework of this work. It is divided into two sectors including a web-based site, that could present the location coordinates and record data of disabled people as to be seen on Google map; and the android site. The system can be linked to Google API to display the application on both Android and the website. [16] There is research before this, which is Expert Systems (ES), Geographic Information Systems (GIS) and environmental decision support systems (EDSS) for ecological applications. General engineering, a design in a landfill and waste disposal use specific management to solve complex environmental problems and facilitate using the ability to develop both in hardware and software. It also shows that the adoption of technology and integrating it together. It can evaluate the design of the complete waste disposal in many aspects. [17] However, this work is extended from previous work and changed to another platform by combining GIS and DSS: for web frontend, using AngularJS and jquery technology over a Google API, and second, for mobile application, using node.js. The GIS technology uses the following to support data access and processing in both web-based and mobile application platform. The prototype DSS framework was applied to simulate the disabled facilities around the Songkhla province and other public areas. 


\section{Methodology}

There was a research that used Multiview 2 framework for GIS development. [16] The study suggested that the system implementation should consider four main issues which included: the organization analysis, the technical analysis of the socio-technical system, the information system format and the software development.

This research conduct data from both quantitative and qualitative data, design and tools, in pursuit to build the GIS-DSS conceptual framework. Mixed methods research is more specific in that it includes the mixing of qualitative and quantitative data, techniques, methodologies, and paradigms in the study. Some research in information systems uses a mixed method by using both quantitative and qualitative methods. For example, the use of quantitative research methods was from the first survey in the first step and also was the idea of quantitative data using the principle of explaining. Moreover, the use of quantitative research methods is to increase accuracy and promote the concept more clearly.

The concept of the GIS-DSS could extend the Multiview 2 framework as Fig. 1. There are four decision-making tools including support tools; models, methods or theories; management or DSS; and integration framework systems. [18]

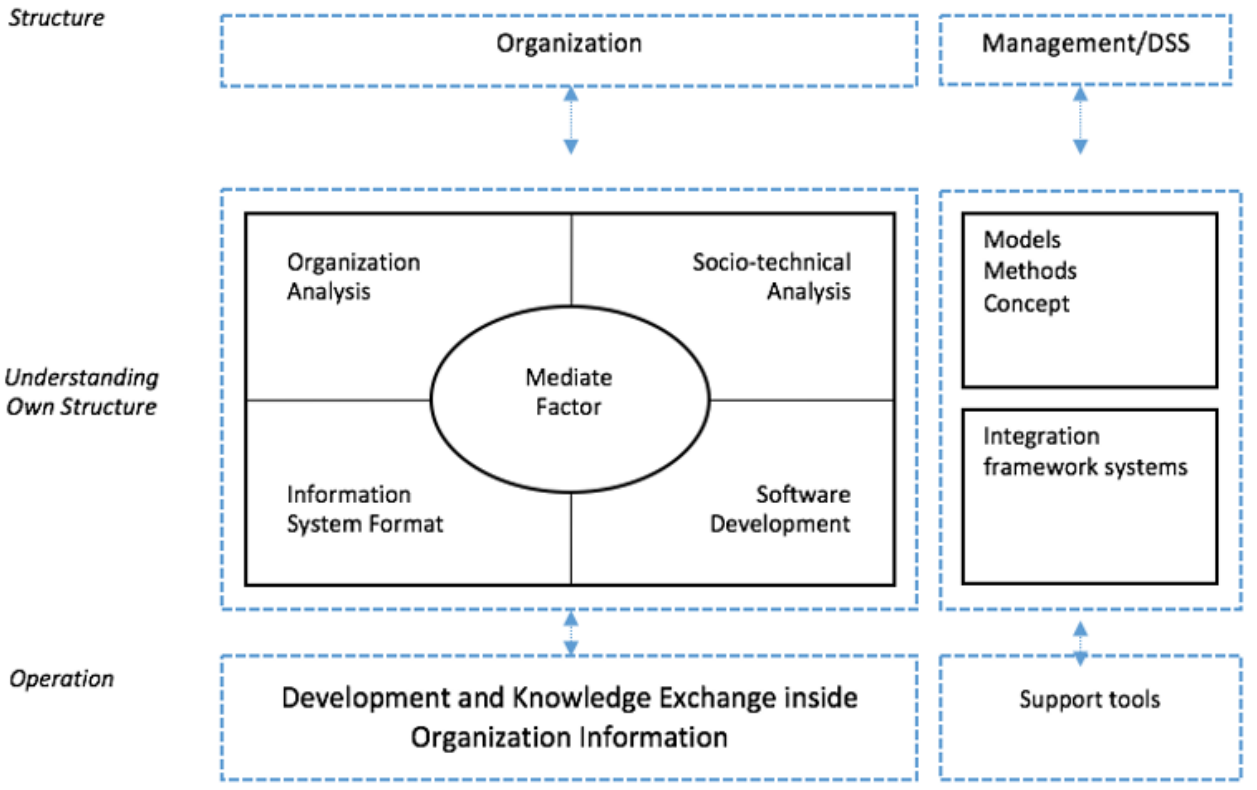

Fig. 1. Multiview 2 Conceptual Framework GIS-DSS Development

\subsection{Support tools}

The support tools are linked to the Multiview 2 conceptual framework regarding tools to develop software after it was designed, in which the understanding of the own structure section of the Multiview 2 is required. This integrated GIS and DSS together and implemented on two platforms. First, for web frontend, using AngularJS and jquery technology over a Google Maps API, and second, for mobile application, using node.js. 
The GIS technology is used to support data access and process in both web-based and mobile application platform. Details are in the following section.

\subsubsection{AngularJS}

AngularJS is a JavaScript framework developed by Google to reduce server data usage. It is used to develop a single-page web application and also supports programming languages. To create a single-page application, AngularJS has three components: HTML, CSS, and Javascript.

\subsection{2 jQuery technology}

jQuery is a JavaScript library that is designed to make JavaScript coding easier and easier because JavaScript is a client-side which is hard to code, whether it is in the incompatibility in any Web Browser, DOM or API, and others. Therefore, jQuery combines all of the required objects and functions into a library no matter how many lines of code you write or the amount of JavaScript lines, it can be shortened. jQuery includes the following features: HTML / DOM manipulation, CSS manipulation, HTML event methods, Effects and animations, AJAX, and Utilities.

\subsubsection{Google Maps API}

Google Maps API is a set of Google APIs for developing web applications and mobile applications (Android, iOS) to run maps and suite of Google services to develop applications just like Google. The map has many features, for example, Customizing the map, Map Control, Drawing tools on the map, Directions from one point to another (Directions Service), Elevation Service, Lattitude and Longitude (GeoCoding Service), POI (Point of Interest) and street view. Moreover, it has a data collection service which is a collection of locations regarding from Google, such as hotels, department stores, schools, government offices, and other Places APIs.

\subsubsection{NodeJS}

Node.js is JavaScript programming on the server side. Node.js will include the environment that makes a proper environment to write JavaScript on the server side, such as web server, runtime and so on. It is called platform because of Node.js is known for its speed of processing, so the number applications written with Node.js are increasing rapidly. Also, the application for assisting the development of the website is very smooth. This article will focus on how to use those applications to benefit the website.

\subsection{Models, Methods, Concepts}

Multiview 2 conceptual framework can be integrated with GIS development as the previous section explained. The framework included five main components including the organizational analysis, the technical analysis of the socio-technical systems, the information system format, and the software development. This section GIS-DSS framework highlighted as a model, method, or the concept following the organization concerning design and management of the disabled people in Songkhla province. The 
organization analysis, socio-technical analysis, information system format and software development were used to implement the application. The operation had the development and knowledge exchange within the organization information that was needed, using support tools such as MySQL, Google Maps API, AngularJS, JQuery, and NodeJS.

\subsection{Management/DSS}

This research implement a system followed GIS-DSS based framework. Their research showed the GIS-DSS framework and the development steps of a decision prototype of GISDSS in the case of disabled people in Songkhla province.

\subsection{Integration framework systems}

The integration framework systems also used the frame of models, methods, concepts in DSS sections and the Multiview 2 section. This research employed the mathematical modeling for the prototype the GIS-DSS system. The multi-modal transport problem is based on the simultaneous elastic demand-traffic assignment concepts, which represented in mathematical modeling as followed. [19]

$$
T_{i j}=T_{0} \exp \left(-\lambda C_{i j}\right)
$$

Where $T_{i j}$ is the number of disabled people travel made from origin $i$ to destination $j, T_{0}$ is the free cost travel demand, $C_{i j}$ is the cost for moving from background $i$ to destination $j$ expressed in time units, and $\lambda$ is a parameter for calibration.

\section{Result and Discussion}

This paper integrated GIS and DSS together and implemented on two platforms. First, for web frontend, using AngularJS and jquery technology over a Google API, and second, for mobile application, using node.js, the GIS technology used to support data access and processing in both web-based and mobile application platform.

\subsection{Mobile Application for data collection}

This research uses mobile application for data collection. The group is from 24,609 records. 16 Amphores, eight education levels, nine disability types. The disabled types are moving or physical, hearing impaired, redundant, disability notice, intellectual disability, learning disability, mental or behavioral disorders, autistic, and undefined disability. 


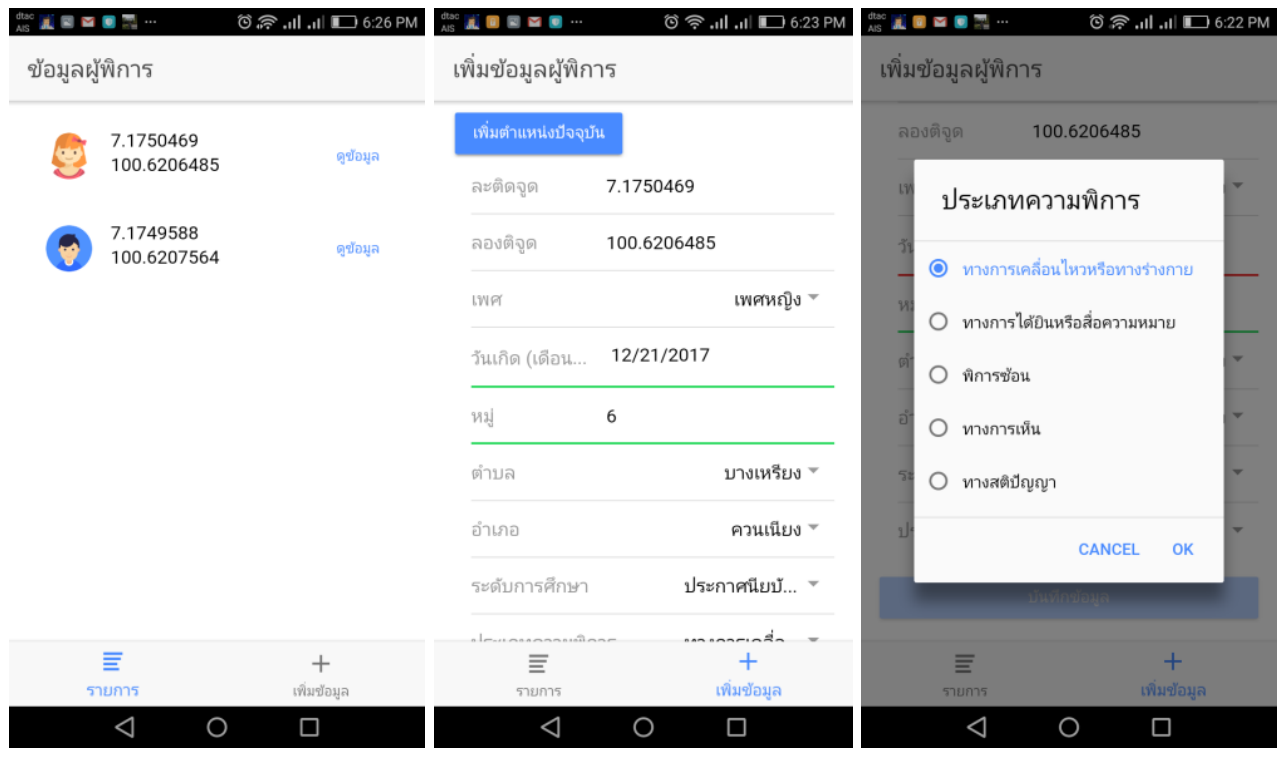

Fig. 2. Mobile application interface

\subsection{Descriptive disabled people data}

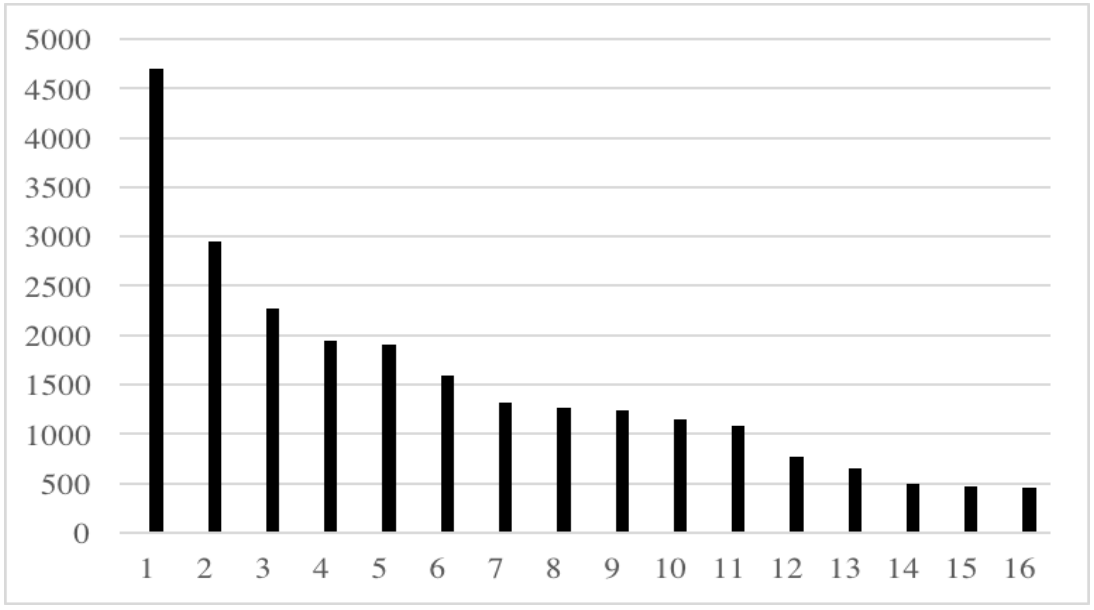

Fig. 3. Total Number of Disabled People in Songkhla Province Separate by District

This graph shows the total number of disabled people in Songkhla Province separated by the district. The figures show in the Fig. 3. linking to the No and District column name in Table 1. It is clear that Hatyai district possesses the distinct highest amount of disadvantaged population among all-district, while the lowest number of impaired belong to Klong Hoi Kong district. We can also see that the three regions with the lowest number of 
disabled, which are Klong Hoi Kong, Namom, and BangKlam had a comparable value of 452, 466 and 497 respectively.

The table below represents the series indicating the district, the number of impaired population in each classified type of disability, and the total number of people with the impediment in each area. The sorts of disability include, Moving or physical, Hearing impaired, Redundant, Disability notice, Intellectual disability, Learning disability, Mental or behavioral disorders and Autistic.

Table 1. Number of Disabled People in each district classified by disabled type

\begin{tabular}{|c|c|c|c|c|c|c|c|c|c|c|}
\hline No & District & $\begin{array}{l}\text { Moving or } \\
\text { physical }\end{array}$ & $\begin{array}{l}\text { Hearing } \\
\text { impaired }\end{array}$ & Redundant & $\begin{array}{l}\text { Disability } \\
\text { notice }\end{array}$ & $\begin{array}{l}\text { Intellectual } \\
\text { disability }\end{array}$ & $\begin{array}{l}\text { Learning } \\
\text { disability }\end{array}$ & $\begin{array}{l}\text { Mental or } \\
\text { behavioral } \\
\text { disorders }\end{array}$ & Autistic & Total \\
\hline 1 & Hat Yai & 2079 & 1068 & 672 & 211 & 352 & 18 & 239 & 67 & 4706 \\
\hline 2 & $\begin{array}{l}\text { Mueang } \\
\text { Songkhla }\end{array}$ & 1360 & 667 & 278 & 146 & 227 & 17 & 240 & 21 & 2956 \\
\hline 3 & Chana & 1003 & 482 & 188 & 163 & 215 & 28 & 179 & 11 & 2269 \\
\hline 4 & Ranod & 955 & 362 & 195 & 145 & 159 & 5 & 128 & 2 & 1951 \\
\hline 5 & Singha Nakhon & 886 & 362 & 212 & 140 & 130 & 7 & 166 & 8 & 1911 \\
\hline 6 & Sadao & 697 & 288 & 245 & 110 & 111 & 15 & 110 & 16 & 1592 \\
\hline 7 & Sathing Phra & 629 & 270 & 119 & 105 & 119 & 1 & 79 & 1 & 1323 \\
\hline 8 & The-pa & 567 & 289 & 141 & 97 & 101 & 6 & 59 & 5 & 1265 \\
\hline 9 & Rattapoom & 586 & 243 & 108 & 86 & 140 & 11 & 59 & 7 & 1240 \\
\hline 10 & Nathavee & 508 & 267 & 97 & 82 & 105 & 4 & 87 & 4 & 1154 \\
\hline 11 & Saba Yoi & 506 & 157 & 117 & 102 & 102 & 7 & 83 & 4 & 1078 \\
\hline 12 & Kuan Niang & 337 & 197 & 65 & 59 & 63 & 8 & 39 & 6 & 774 \\
\hline 13 & Krasaesin & 278 & 119 & 107 & 56 & 45 & 7 & 45 & & 657 \\
\hline 14 & BangKlam & 230 & 79 & 52 & 46 & 58 & 8 & 22 & 2 & 497 \\
\hline 15 & Namom & 219 & 110 & 30 & 24 & 37 & 0 & 44 & 2 & 466 \\
\hline 16 & Klong Hoi Kong & 169 & 109 & 68 & 40 & 39 & 8 & 18 & 1 & 452 \\
\hline
\end{tabular}

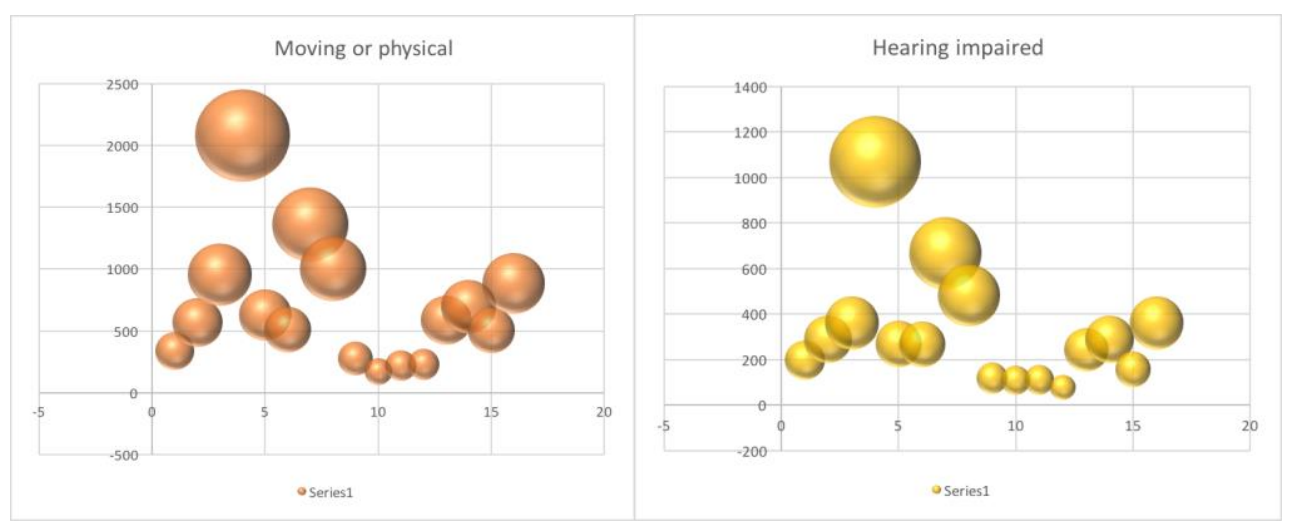

(a)

(b) 


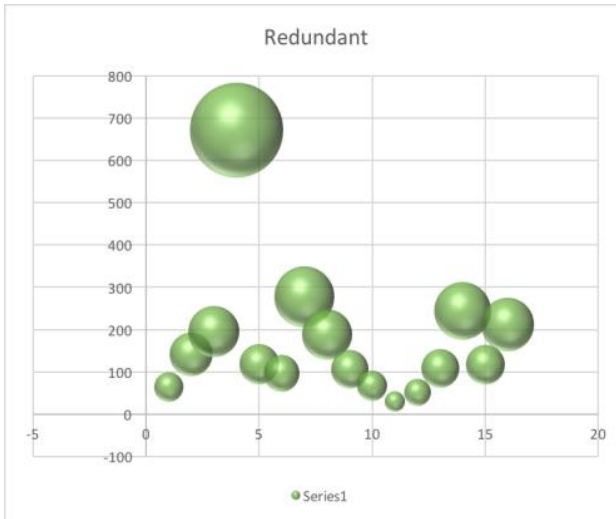

(c)

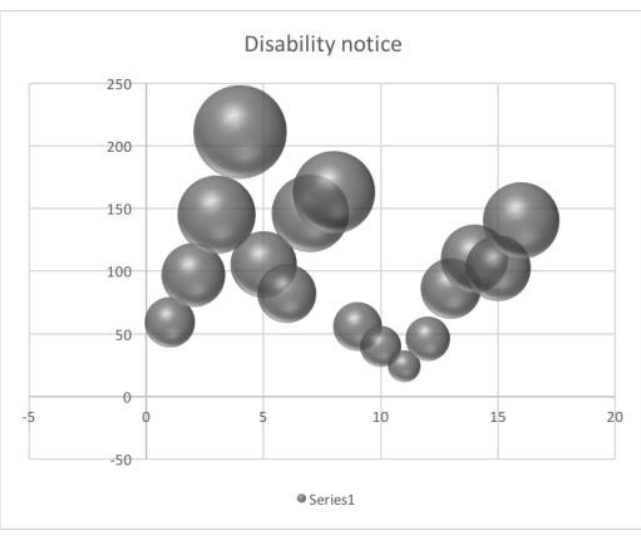

(d)

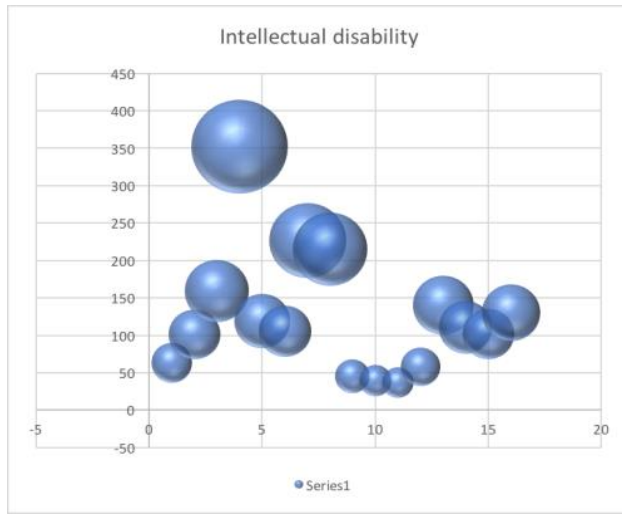

(e)

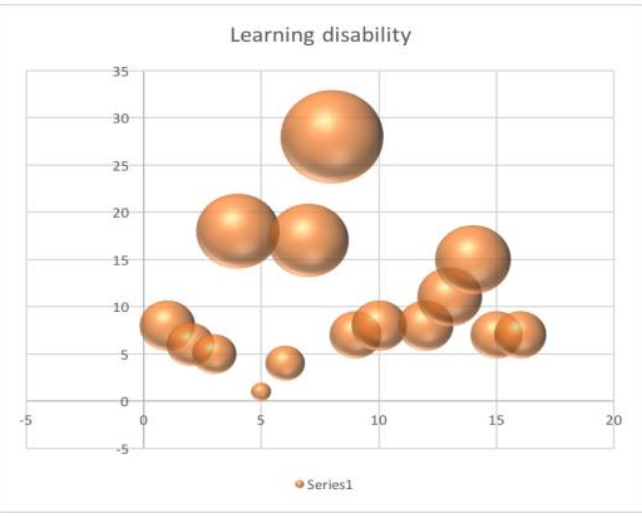

(f)

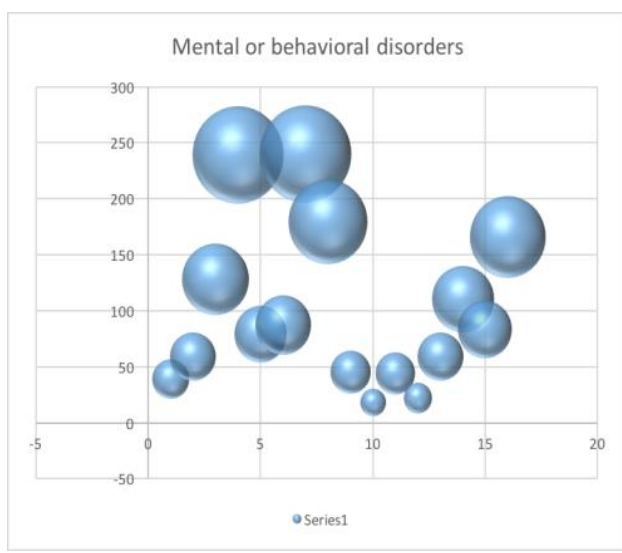

(g)

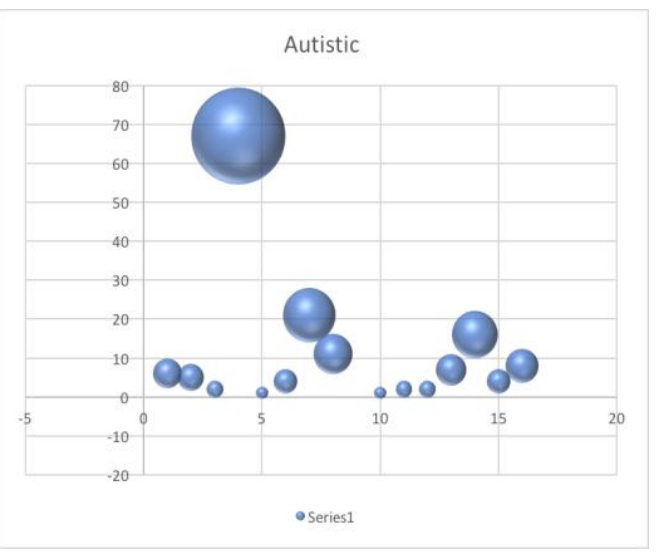

(h) 
Fig. 4. (a) Moving or physical

(b) Hearing impaired

(c) Redundant

(d) Disability notice

(e) Intellectual disability

(f) Learning disability

(g) Mental or behavioral disorders

(h) Autistic

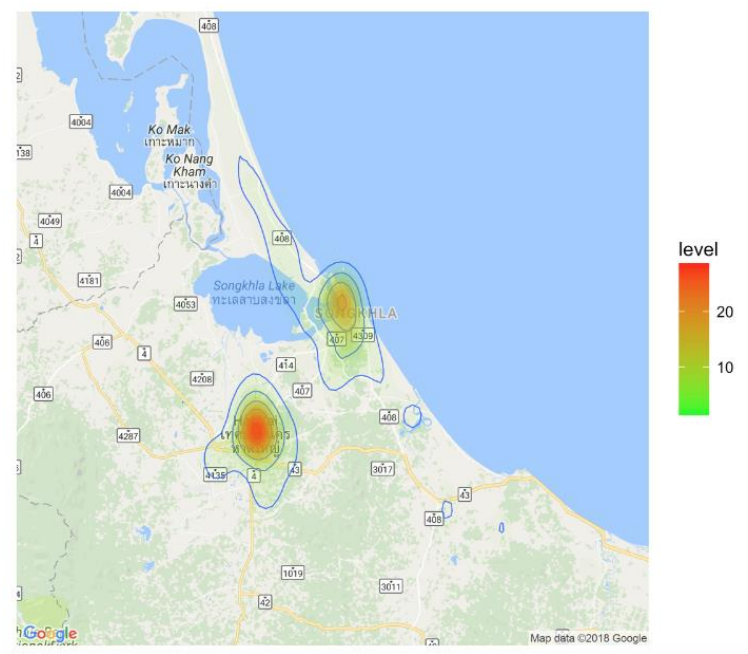

Fig. 5. The area where the disabled are densely populated.

Fig. 4. shows the density of the disabled population comparison among districts in Songkhla Province separated by type of disability. There are (a) Moving or physical (b) Hearing impaired (c) Redundant (d) Disability notice (e) Intellectual disability (f) Learning disability (g) Mental or behavioral disorders (h) Autistic. Including, the number represents the district in Songkhla (1) Kuan Niang, (2) The-pa, (3) Ranod, (4) Hat Yai, (5) Sathing Phra, (6) Nathavee, (7) Muang Songkhla, (8) Chana, (9) Krasaesin, (10) Klong Hoi Kong, (11) Namom, (12) Bangklam, (13) Rattapoom, (14) Sadao, (15) Saba Yoi, and (16) Singha Nakhon, respectively.

Table 1 shows that the total number of disabled people in the first three are Hat Yai, Mueang Songkhla, and Chana, respectively. Fig. 5. also supports that the area of the densely populated of the disabled people is located in Hatyai, and Mueang Songkhla. Considering the first three categories of disability, the first three categories of moving or physical, hearing impaired, intellectual disability were Hatyai, Songkhla, and Chana districts respectively. However, considering the redundant limitation and autistic; The first 3 are Hat Yai, Mueang Songkhla, and Sadao; considering disabilities. It can be seen that the first 3 are Hat Yai, Chana, and Mueang Songkhla. If it is learning disability, it can be seen that the first three are Hat Yai and Mueang Songkhla, and if it is mental or behavioral disorders, the first three will be Mueang Songkhla, Hat Yai, and Chana, respectively. 


\section{Conclusion}

This research introduced the way to integrate GIS and DSS designed framework and implemented in the real situation in two platforms. First, for web frontend, using AngularJS and jquery technology over a Google API, and second, for mobile application, using node.js, the GIS technology used to support data access and processing in both web-based and mobile application platform. Multiview 2 framework which included GIS and DSS was applied to simulate the disabled facilities around the Songkhla province and other public areas. This research intends to develop the prototype GIS-DSS into a full-fledged tool. Decision models were used in the design of appropriate environments for the disabled. The real data was used for decision making and provide the suggested solution. Integration of tools made the complex system makes the planning easier to solve problems for senior executives and budget management. This research also showed some suggestion for Songkhla Province. It also explains the problem of system redundancy that may occur. To prevent future smart city problems.

\section{References}

1. W. Soidokson, A. Ingard, S. Kusupornchareon, and S. Rattana, 'Development of English teaching for visually handicapped children', Acad. J. King Mongkut Univ. Technol. North Bangk., vol. 20, no. 3, pp. 581-590, Dec. (2010).

2. K. Kotkeaw, D. Suriyawong, P. Imthongkam, and J. So-in, 'The app manages audiobooks for the visually impaired on mobile devices.', pp. 779-784, (2017).

3. Y. Hatthasin, T. Tajai, and A. Na-Takuatoong, 'A Pinpoint Material on a Barcode Symbol of the Barcode Readable System for the Blind Students', in The 9th National Conference on Computing and Information Technology, pp. 940-945, (2013).

4. A. Kusiyarangsit, 'Computer Teaching for Mass Communication for Visually Impaired Students', RMUTP Res. J., vol. 8, no. 1, pp. 152-163.

5. P. Tongprakob and Y. Limpiyakorn, 'Increasing Efficiency of Data Accessibility on Web for Visually Impaired', Inf. Technol. J., vol. 10, no. 1, pp. 8-14, Jun. (2014).

6. W. Suranun and M. Ketcham, 'Control of Smartphone Operation with Eye Detection Technique On the Android operating system for arm disabilities', presented at The Eleventh National Conference on Computing and Information Technology, pp. 181$186,(2015)$.

7. J. Moramat and K. Viriyapant, 'Geographic Information System to support limit allocation of Loans for People with Disabilities', in The 9th National Conference on Computing and Information Technology, pp. 203-208, (2013).

8. V. Cañal-Fernández and M. Hernández Muñiz, 'An exploratory analysis of disabled people accessibility to urban public transport: the use of Geographical Information Systems', Investig. Reg. - J. Reg. Res., no. 30, pp. 79-101, (2014).

9. S. Thanachai and N. Wisitpongpan, 'System for help and notification of fallen persons for the elderly.', in The 6TH National Conference on Computing and Information Technology NCCIT2010-163, pp. 55-60, (2010).

10. N. Thawornwong, A. Agkaraserttang, and P. Makkasorn, 'Designing of Falls Detection For Elderly by Using Tilt Sensor', Naresuan Univ. J., vol. 2, no. 92, pp. 43-46, (2011).

11. C. Doukas, V. Metsis, E. Becker, Z. Le, F. Makedon, and I. Maglogiannis, 'Digital cities of the future: Extending @home assistive technologies for the elderly and the disabled', Telemat. Inform., vol. 28, no. 3, pp. 176-190, Aug. (2011).

12. M. Górnik-Durose and A. Wąsik, 'Market regulations in social relationships and Attitudes towards Disabled People', Stanislaw Juszczyk, p. 275. 
13. K. Jayakar, C. Liu, G. Madden, and E.-A. Park, 'Promoting Broadband and ICT Access for Disabled Persons: Comparative Analysis of Initiatives in Asia-Pacific Region', Inf. Soc., vol. 31, no. 4, pp. 299-314, Aug. (2015).

14. S. Snow, B. McMahon, S. McKenzie, K. Radke, I. Verlaat, and L. Buys, 'Designing for Collections: Building Histories, Sharing the Spectacle', in Proceedings of the Annual Meeting of the Australian Special Interest Group for Computer Human Interaction, New York, NY, USA, pp. 299-303, (2015).

15. F. De Backere, P. Bonte, S. Verstichel, F. Ongenae, and F. De Turck, 'The OCarePlatform: A context-aware system to support independent living', Comput. Methods Programs Biomed., vol. 140, pp. 111-120, Mar. (2017).

16. S. Tongkaw, 'GIS Application Management for Disabled People', IOP Conf. Ser. Mater. Sci. Eng., vol. 226, no. 1, p. 012112, (2017).

17. A. F. Lukasheh, R. L. Droste, and M. A. Warith, 'Review of expert system (ES), geographic information system (GIS), decision support system (DSS), and their applications in landfill design and management', Waste Manag. Res., vol. 19, no. 2, pp. 177-185, (2001).

18. K. W. J. Malafant and D. P. Fordham, 'GIS, DSS and integrated scenario modeling frameworks for exploring alternative futures', WIT Trans. Ecol. Environ., vol. 22, (1970).

19. G. Arampatzis, C. T. Kiranoudis, P. Scaloubacas, and D. Assimacopoulos, 'A GISbased decision support system for planning urban transportation policies', Eur. J. Oper. Res., vol. 152, no. 2, pp. 465-475, Jan. (2004). 